\title{
EXPLORING THE RELATIONSHIP BETWEEN HIGHWAY GEOMETRIC CHARACTERISTICS AND CAPACITY LOSS
}

\author{
Ibrahim Hassan Hashim ${ }^{1}$, and Talaat Ali Abdel-Wahed ${ }^{2}$ \\ ${ }^{1}$ Civil Engineering Department, Minoufiya University, Shebin El-Kom, Egypt \\ ${ }^{2}$ Civil Engineering Department, Sohag University, Sohag, Egypt
}

\begin{abstract}
:
The main aim of this paper is to explore the impact of highway geometric characteristics on capacity at tangents and horizontal curves as well as on capacity loss at the change from tangent to curve. Vehicle speeds and flows on the two successive elements (tangent and curve) were recorded for each five-minute intervals during the survey period, for twelve rural two-lane road sites. A capacity estimation method based on extrapolation from a fundamental diagram representing the relationship between traffic flow and density was used. The effect of different vehicle types was considered by converting them into equivalent passenger car units. Regression analysis was used to investigate the relationships between geometric characteristics and capacity for tangents, curves and capacity loss between the two elements. The significant independent variables for tangents are lane width, shoulder width and tangent length. In the case of curves, the significant independent variables are curve radius and lane width. The best model that shows the relationship between capacity loss and geometry characteristics includes only curve radius. Based on this model, a curve radius with $600 \mathrm{~m}$ appears to be the threshold value to diminish the capacity loss between tangent and succeeding curve. The models are very useful and can be used to deal with capacity analysis and evaluation, especially for the area under study.

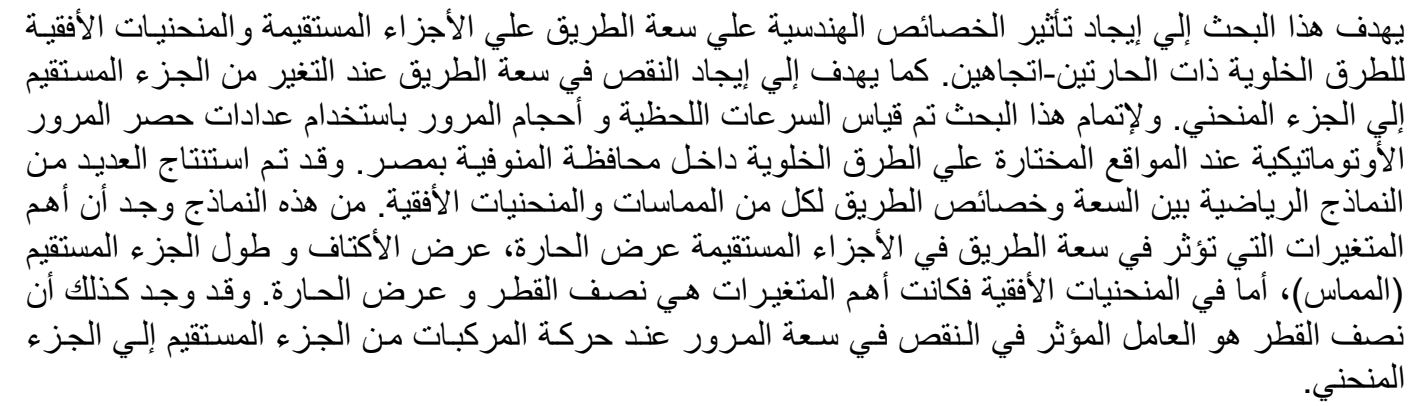

Keywords: Capacity - Highway Geometry - Horizontal Curve - Flow/Density Relationship Regression Analysis.
\end{abstract}

\section{INTRODUCTION}

Estimation and knowledge of roadway capacity are essential in the planning, design and operation of transportation facilities. Capacity is greatly influenced by roadway, traffic and driver conditions. It is defined in the HCM 2000 as "the maximum hourly rate at which persons or vehicles can be reasonably expected to traverse a point or a uniform segment of a lane or roadway during a given time period under prevailing roadway, traffic, and control conditions" [1]. Roadway conditions may contain all geometric parameters describing the roadway such as the type of facility, lane width, shoulder width, and horizontal and vertical alignments. Horizontal alignment, especially horizontal curve characteristics, can have a substantial impact on traffic flow. For example, on sharp curves, vehicles may reduce their speed or increase the longitudinal gaps consequently the flow is reduced. Horizontal alignment is composed of either straight elements (tangents) or curved elements. Each of these elements has its own geometric characteristics that influence the maximum traffic flows that can be achieved. Therefore, capacity flows may be differed from one element to another. Roadway capacity loss for two successive elements is the negative difference in road capacity between these two elements. This study supposes that the capacity value is affected by highway geometry, as indicated in Figure 1, when road element changes from tangent to curve. Although the impact of highway geometry on capacity was studied by many researchers, it seems that no research has been done to investigate the impact of horizontal alignment characteristics, especially curve radius, on capacity loss. The present study was undertaken to estimate 
the impact of highway geometry, with specific reference to horizontal alignment characteristics, on capacity and capacity loss using traffic and geometry data from rural two-lane roads in Minoufiya Governorate, Egypt. The results of this research should help highway and traffic engineers, and researchers to deal with capacity analysis more accurately.

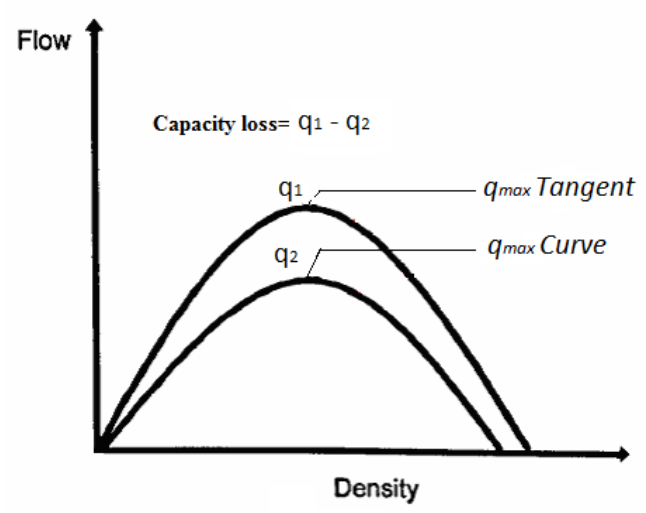

Fig. 1 Influence of Road Geometry on Flow-Density Relationship

\section{BACKGROUND STUDIES}

Previous studies on the impact of roadway characteristics on capacity and capacity loss were reviewed. Examples of these studies are presented in this section.

Polus et al. [2] investigated the traffic flow and capacity characteristics on two-lane highways. Several models were developed for the relationships between flow parameters. The relationships varied from one road to another and were dependent on the characteristics of each site. They concluded that the capacity value is sensitive to the geometric characteristics of each site.

Nakamura [3] has discussed the concept of highway capacity in Japan. He has suggested adjustment factors (YL) for lane width (WL) less than $3.25 \mathrm{~m}$ as $\mathrm{YL}=0.24 \mathrm{WL}+0.22$

Gibreel et al. [4] studied the relationship between geometric design consistency and highway capacity based on a three-dimensional analysis, considering combinations of vertical and horizontal curves. They have compared the actual service flow rate as determined based on the observed traffic flow data, and the theoretical flow rate as calculated based on highway capacity analysis. The results show that the actual service flow rate is always smaller than the theoretical one with ratio ranging from 0.74 to 0.98 . Gibreel et al. argued that the difference is due the geometric design inconsistencies. Therefore, a new adjustment factor called the consistency factor is developed to account for the difference.

Chandra and Kumar [5] investigated the impact of lane width on capacity using data from ten sections of two-lane roads in India. They found that the capacity (C) in PCU/h of two-lane road increases with total width (W) of the carriageway and the relationship between the two follows a second degree curve as: $C=-2184-22.6 W^{2}+857.4 W$. The relationship can provide a capacity estimate for twolane roads with a carriageway width ranging from 5.5 to $8.8 \mathrm{~m}$.

Yang and Zhang [6] investigated the impact of the number of lanes on highway capacity using field traffic flow data from Beijing. The findings showed that average capacity per lane decreases with increasing number of lanes on uninterrupted highway segments. Thus, the marginal decrease rate of average capacity per lane with increasing number of lanes is around $6.7 \%$.

Ben-Edigbe and Ferguson [7] investigated the impact of road condition, pavement distress, on capacity and capacity loss at two-way roads based on observations of eight sites in Nigeria. A capacity estimation method based on extrapolation from a fundamental diagram representing the relationship between traffic flow and density was used. Capacities were estimated for without distress and with distress road sections. It was found that capacities on without distress and with distress sections were differed significantly. Also, Chandra [8] studied the effect of road roughness on capacity of two-lane roads in India. The study found that the free flow speed of a vehicle decreases with the roughness of the road surface. The effect of roughness is more apparent on the speed of passenger cars than of heavy vehicles. The speedvolume relationships drawn at different sections of two-lane rural roads indicate that the capacity decreases with an increase in the road roughness.

Chin et al. [9] investigated the impact of temporary events on capacity loss. Temporary capacity losses due to work zones, crashes, breakdowns, adverse weather, and sub-optimal signal timing resulted in an estimated 2.3 billion vehicle-hours of delay on U.S. freeways and principal arterials in 1999. Assuming average vehicle occupancy of 1.6 persons, this translates into 3.7 billion person-hours of delay.

Kim and Elefteriadou [10] Developed a new microscopic simulation model called TWOSIM for the estimation of capacity for two-way two-lane highway (TWTLHW) under a variety of prevailing traffic and geometric conditions. These include percentage of traffic per direction, presence of a passing zone, a horizontal curve, a driveway, an upgrade, and heavy vehicles. Kim and Elefteriadou concluded that Capacity for TLTWHW using field data has not been observed frequently because there are a very limited number of sites operating at capacity. The simulation results showed that the capacity was found to vary by the average free flow speed. Some other results found that capacity decreased by $12-26 \%$ as a function of the turning curb radius and percentage of turning flow when 
there was a driveway. Capacity decreased by $3-17 \%$ as a function of curb radius when there was a horizontal curve. With an increasing proportion of trucks (10-20\%), when there was a driveway, capacity decreased by $10-23 \%$, when there was a horizontal curve it decreased by 3-36\%, when there was an upgrade section, it decreased by $11-40 \%$.

\section{DATA COLLECTION AND PREPARATION}

The paper used twelve road sites with various geometric characteristics from intercity rural twolane roads, in Minoufiya Governorate, Egypt, with a speed limit of $60 \mathrm{~km} / \mathrm{h}$. Each site is consisted of one horizontal curve and the adjoining tangent. All of the chosen sites are located on relatively level terrain to minimize or avoid the effect of the longitudinal gradient. All geometry data was estimated using automatic and manual field surveys. Forward visibility (sight distance) was measured in the field manually according to the method used by Hashim [11]. The road geometry characteristics that estimate in the filed include lane width, shoulder width, forward visibility, number of side access points, curve radius, superelevation, and tangent length. Tables 1 and 2 show the characteristics of the selected sites as well as their limits for tangent and curve elements.
Roadside automatic traffic counters were used to conduct the traffic surveys. The survey placed two automatic traffic counters for at least 7 hours at the 12 sites. The configuration of the counter positions is presented in Figure 2. Based on this configuration, the traffic characteristics were surveyed at the midpoint of the tangent (A) preceding the curve, and midpoint of curve (B). This configuration could help in studying the impact of horizontal alignment characteristics on flow and other traffic stream characteristics. Collection of traffic data was carried out in working days during the daylight hours. During data collection periods, the weather was clear and the pavement was dry.

Data set at each direction of travel on each site was divided into 5-minutes intervals. In each interval, vehicle counts were multiplied by twelve to convert them into flow rates. The average travel speed was equal to the output mean speed. The density can be calculated from the following equation:
Density $(K)=$ Flow Rate $(q) /$ Average Travel Speed (ATS)
Description of field traffic data including data collecting duration, vehicular counts, percentage of heavy vehicles and buses, and directional split ratio is provided in Table 3.

Table 1, Geometric Characteristics of the Selected Sites (Tangent Elements)

\begin{tabular}{|c|c|c|c|c|c|}
\hline $\begin{array}{c}\text { Site } \\
\text { No }\end{array}$ & $\begin{array}{c}\text { Lane } \\
\text { Width } \\
(\mathrm{LW}), \mathrm{m}\end{array}$ & $\begin{array}{c}\text { Shoulder } \\
\text { Width, } \\
\text { averaged } \\
\text { from both } \\
\text { directions } \\
(\mathrm{SW}), \mathrm{m}\end{array}$ & $\begin{array}{c}\text { Tangent } \\
\text { Length } \\
\left(\mathrm{T}_{\mathrm{L}}\right), \mathrm{m}\end{array}$ & $\begin{array}{c}\text { Forward } \\
\text { Visibility } \\
(\mathrm{FV}), \mathrm{m}\end{array}$ & $\begin{array}{c}\text { No. of Side } \\
\text { Accesses, } \\
\text { in both } \\
\text { directions } \\
\text { (SA) }\end{array}$ \\
\hline 1 & 3.50 & 1.85 & 768 & 360 & 4 \\
\hline 2 & 2.80 & 1.28 & 260 & 286 & 2 \\
\hline 3 & 3.50 & 1.9 & 904 & 396 & 9 \\
\hline 4 & 3.40 & 1.7 & 822 & 382 & 7 \\
\hline 5 & 3.35 & 1.2 & 779 & 367 & 7 \\
\hline 6 & 3.10 & 1.3 & 579 & 180 & 8 \\
\hline 7 & 3.25 & 1.4 & 488 & 196 & 6 \\
\hline 8 & 3.45 & 1.2 & 180 & 204 & 1 \\
\hline 9 & 3.00 & 1.25 & 523 & 198 & 7 \\
\hline 10 & 3.25 & 1.35 & 565 & 202 & 7 \\
\hline 11 & 3.00 & 1.35 & 679 & 320 & 3 \\
\hline 12 & 3.10 & 1.45 & 495 & 199 & 6 \\
\hline Summary Statistics & \multicolumn{5}{|l|}{} \\
\hline Avg. & 3.23 & 1.44 & 586.83 & 274.17 & 5.58 \\
\hline Max. & 3.50 & 1.90 & 904 & 396 & 9 \\
\hline Min. & 2.80 & 1.20 & 180 & 180 & 1 \\
\hline SD & 0.23 & 0.25 & 219.36 & 85.95 & 2.50 \\
\hline
\end{tabular}


Table 2, Geometric Characteristics of the Selected Sites (Curve elements)

\begin{tabular}{|c|c|c|c|c|c|}
\hline $\begin{array}{l}\text { Site } \\
\text { No. }\end{array}$ & $\begin{array}{c}\text { Lane } \\
\text { Width } \\
(\mathrm{LW}) \text {, } \\
\text { m }\end{array}$ & $\begin{array}{l}\text { Shoulder } \\
\text { Width, } \\
\text { averaged } \\
\text { from both } \\
\text { directions } \\
(\mathrm{SW}), \mathrm{m}\end{array}$ & $\begin{array}{l}\text { Forward } \\
\text { Visibility } \\
(\mathrm{FV}), \mathrm{m}\end{array}$ & $\begin{array}{l}\text { Curve } \\
\text { Radius } \\
(\mathrm{R}), \mathrm{m}\end{array}$ & $\begin{array}{c}\text { Superelevation } \\
\text { (e), \% }\end{array}$ \\
\hline 1 & 3.65 & 1.60 & 235 & 228 & 3.3 \\
\hline 2 & 3.00 & 1.30 & 491 & 148 & 3.6 \\
\hline 3 & 3.50 & 1.95 & 241 & 586 & 2.79 \\
\hline 4 & 3.40 & 1.90 & 185 & 402 & 1.01 \\
\hline 5 & 3.40 & 1.60 & 265 & 370 & 1.95 \\
\hline 6 & 3.20 & 1.55 & 173 & 100 & 2.6 \\
\hline 7 & 3.50 & 1.65 & 167 & 146 & 2.75 \\
\hline 8 & 3.45 & 1.35 & 185 & 128 & 0.41 \\
\hline 9 & 3.20 & 1.55 & 170 & 157 & 3.0 \\
\hline 10 & 3.25 & 1.35 & 244 & 164 & 1.27 \\
\hline 11 & 3.30 & 1.50 & 153 & 298 & 1.78 \\
\hline 12 & 3.10 & 1.65 & 209 & 120 & 2.2 \\
\hline \multicolumn{6}{|c|}{ Summary Statistics } \\
\hline Avg. & 3.33 & 1.58 & 226.50 & 237.25 & 2.22 \\
\hline Max. & 3.65 & 1.95 & 491 & 586 & 3.6 \\
\hline Min. & 3.00 & 1.30 & 153 & 100 & 0.41 \\
\hline SD & 0.19 & 0.2 & 90.84 & 148.56 & 0.97 \\
\hline
\end{tabular}

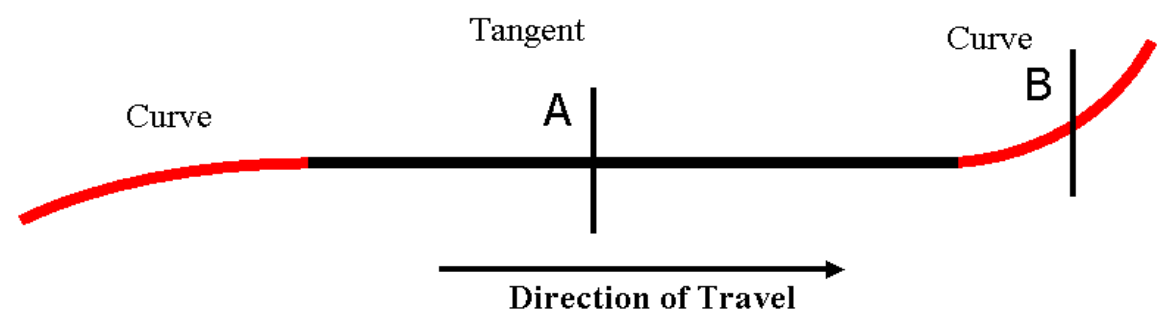

Fig. 2 Position of Automatic Traffic Counters for Study Sites

Table 3, Field Traffic Data for Study Sites

\begin{tabular}{|c|c|c|c|c|}
\hline $\begin{array}{c}\text { Site } \\
\text { No. }\end{array}$ & $\begin{array}{c}\text { Duration of data } \\
\text { collection (hours) }\end{array}$ & $\begin{array}{c}\text { Traffic counts in both } \\
\text { directions (vehicles) }\end{array}$ & $\begin{array}{c}\text { Percentage of heavy } \\
\text { vehicles and buses (\%) }\end{array}$ & $\begin{array}{c}\text { Directional split ratio } \\
(\%)\end{array}$ \\
\hline 1 & 8.25 & 3085 & 5.6 & 51 \\
\hline 2 & 8.25 & 1534 & 4.1 & 52 \\
\hline 3 & 8.10 & 1954 & 7.2 & 50 \\
\hline 4 & 8.10 & 4891 & 3.6 & 54 \\
\hline 5 & 8.10 & 3214 & 5.3 & 51 \\
\hline 6 & 8.00 & 2584 & 4.2 & 55 \\
\hline 7 & 8.00 & 5313 & 2.8 & 52 \\
\hline 8 & 7.33 & 1558 & 3.8 & 53 \\
\hline 9 & 7.35 & 968 & 6.2 & 55 \\
\hline 10 & 8.25 & 799 & 5.1 & 53 \\
\hline 11 & 9.45 & 960 & 5.5 & 52 \\
\hline 12 & 8.00 & 2363 & 3.6 & \\
\hline
\end{tabular}


Figure 3 presents an example of the relationship between Flow Rate and Density at one of the study sites for one direction for both elements (tangent and curve); other sites show relatively similar patterns. The relationship shows that the traffic stream is in un-congested state, as these roads usually carry relatively low traffic volumes [12]. The relationships also show the impact of horizontal alignment/element type (tangent, horizontal curve) on traffic flow parameter.

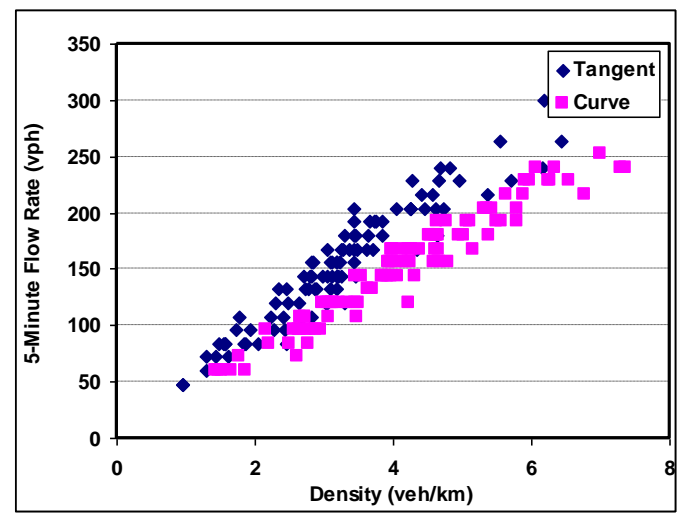

Fig. 3 Flow Rate and Density Relationship for One Study Site, at One Direction of Travel

\section{CAPACITY AND PASSENGER CAR UNIT ESTIMATION METHODOLOGIES}

Roadway capacity is a very important factor that is used in highway planning, design, and evaluation of operational performance [13, 14]. Capacity estimation methodology can be divided into two categories: the direct empirical methods, based on observed traffic flow characteristics; and indirect empirical methods, based on guidelines and simulation models [15]. In this paper, the directempirical method based on the observed volumes, speeds and densities was used. In this method, capacity is either measured directly from the traffic data, if a road section forms a bottleneck, or estimated by extrapolating un-congested flow observations. Harwood et al. [16] developed the HCM 2000 methodology for two-lane, two-way highways. They indicated that capacity conditions are difficult to observe because there are very few twolane two-way highways operating over capacity. In this paper, the critical density can be extrapolated mathematically until the maximum of the $q-k$ function is reached.

The flow-density relationship has been shown by Van Arem et al. [17] and Minderhoud et al. [18] to have a quadratic function. In this form, density (k) is used as the control parameter and flow (q) the objective function, as shown in the following equation: $\quad q=-\beta_{0}+\beta_{1} k-\beta_{2} k^{2}$.The capacity theory underlying the relationship dictates that concavity in the flow density curve must be present for validity. To satisfy the concavity requirement of the flow-density curve, the coefficients signs must return a negative sign or zero for coefficients $\beta_{2}$ and $\beta_{0}$ and a positive sign for $\beta_{1}$, as in the above equation [7]. In theory, where the flow-density relationship has been used to compute roadway capacity, the critical density is reached, when flow becomes maximum, at the summit point. In this paper, traffic capacity can be calculated by the way of quadratic function and the point of the extrapolated curve represents the capacity. This point is a function of critical density and determined by differentiating flow with respect to density. It is worth mentioning that this method was applied before by Ben-Edigbe and Ferguson, in a different application [7].

The effect of different types of vehicles within a traffic stream is considered by converting vehicles into passenger car units (PCU). Several methods are available in the literature to calculate the PCU values. The methods may include headway ratio, speed parameters and actual delay. Speed and vehicles area on the road is another method for calculating PCU [5, 19]. Krammes and Crowley [20] indicated that the variables used to define the level-of-service (LOS) should be used to estimate the PCU values also. The LOS of a highway segment is defined in terms of operating speed [1]. Accordingly, speed is considered a key variable to determine the relative effect of different types of vehicles on the traffic stream. Chandra and Sikdar [19] stated that, the projected rectangular area of each vehicle is considered also another prime variable to determine the PCU. The physical size of a vehicle indicates the pavement occupancy which is crucial in traffic operation. Therefore, the PCU of a vehicle type can be given according to Chandra and Kumar [5] by the following equation:

$$
\mathrm{PCU}_{\mathrm{i}}=\frac{V_{c} / V_{i}}{A_{c} / A_{i}}
$$

where:

$V_{c}$ and $V_{i}=$ mean speeds for cars and type $i$ vehicles, respectively; and

$A_{c}$ and $A_{i}=$ their projected rectangular areas (length $\times$ width) on the road.

In this paper, the PCU values were estimated based on the previous equation at each site for each element separately (i.e. tangent, curve) as this could reflect the effects of road geometry on roadway capacity. The results of the PCU values for the four vehicle categories (motorcycles (MC), Light good Vehicles (LGV), Heavy Good Vehicles (HGV) and Buses (BUS)) vary from 0.22 to $0.30,1.4$ to $1.79,3.9$ to 6.0 , and 3.0 to 4.0 , for each category respectively. 


\section{ANALYSIS AND RESULTS}

\subsection{Estimation of Capacity and Capacity Loss}

The analysis is based on observations of onedirection of traffic flow (from tangent to curve), as indicated in Figure 2. The steps to determine the capacity loss between tangent and succeeding horizontal curve elements at one of the study sites are presented, as follows:

Step 1: Using tangent and curve data, traffic volumes for each 5-minute interval for each vehicle class were converted to 5-minute flow rates in $(\mathrm{PCU} / \mathrm{h})$, after applying the PCU values. Densities were calculated in $(\mathrm{veh} / \mathrm{km})$ using the following relation:

\section{Density $(k)=$ Flow $(q) /$ Average Travel Speed} (ATS)

Step 2: The quadratic relationships between flow and density were calibrated and the model coefficients for both tangent and curve were determined as:

$$
\begin{gathered}
q_{\text {tangent }}=-\beta_{o}+\beta_{1} k-\beta_{2} k^{2}=-16.90+75.02 k-1.18 k^{2} \\
q_{\text {curve }}=-\beta_{o}+\beta_{1} k-\beta_{2} k^{2}=-11.34+79.83 k-1.66 k^{2}
\end{gathered}
$$

The models coefficients have the signs that satisfy the concavity requirements; also they were significantly different from zero at the $95 \%$ confidence level. Also the resulting coefficients of determinations $\left(\mathrm{R}^{2}\right)$ are 0.94 and 0.90 for tangent and curve respectively.

Step 3: By differentiating $q$ with respect to $\mathrm{K}$; for a maximum value of flow $(\mathrm{q}): \partial \mathrm{q} / \partial \mathrm{K}=0$, the critical densities for both straight and curve were determined as:

$$
\begin{aligned}
K_{\text {critical } \text { (tangent) }}=75.02 /(2 \times 1.18)=30.70 \mathrm{PCU} / \mathrm{km} \\
K_{\text {critical } \text { (curve) }}=79.83 /(2 \times 1.66)=24.05 \mathrm{PCU} / \mathbf{k m}
\end{aligned}
$$

Step 4: The computed critical densities were substituted into the quadratic equations in step 2 to determine the maximum flow per road elements as follows: q $\max$ (tangent) $=1172 \mathrm{PCU} / \mathrm{h}$; and $\mathrm{q} \max$ (curve) $=948 \mathrm{PCU} / \mathrm{h}$. Therefore the capacity loss at this site $=1172-948=224 \mathrm{PCU} / \mathrm{h}$ and consequently the percentage of Loss $=224 / 1172=19.1 \%$.

These steps were applied to all sites for both tangents and curves. The resulting models, in the majority of the cases, have the expected signs and the coefficients of determinations $\left(\mathrm{R}^{2}\right)$ are in general greater than 0.85 . Table 4 summarizes the capacity values for both curve and tangent elements and the percentage of capacity loss in each site.

Looking to results presented in Table 4 indicates that capacity values at all sites didn't reach the HCM 2000 value (1700 PCU/h for one direction under ideal condition). This could be due to several reasons, as follows:

- All roads are classified as class II, according to the HCM 2000, which serves shorter trips;

- All roads have posted low speed limit of 60 $\mathrm{km} / \mathrm{h}$. Polus et al. [21] stated that speed limit can explain more than 50 percent of the variability in operating speed;

- The site characteristics are relatively far from the ideal conditions;

- The nature of study roads (agriculture roads), with restricted circumstances from the two directions (i.e. trees), may affect the forward visibility and therefore the capacity values; and

- Capacity depends on roadway, traffic and driver behavior conditions. Therefore, the values obtained could reflect the conditions for road, traffic and driver characteristics of the area under study.

Based on the results in Table 4, it can be noticed that the percentage of capacity loss was mainly depending on the radius of horizontal curve (see also Table 2). However, this was verified statistically using the appropriate statistical analysis, as in Section 5.3.

Table 4, Capacity Values and Percentage of Capacity Loss in each Site

\begin{tabular}{|c|c|c|c|}
\hline Site no. & $\begin{array}{c}\text { Capacity at tangent } \\
\text { elements (PCU/h) }\end{array}$ & $\begin{array}{c}\text { Capacity at curve } \\
\text { elements (PCU/h) }\end{array}$ & $\begin{array}{c}\text { Capacity Loss } \\
(\%)\end{array}$ \\
\hline 1 & 1172 & 948 & 19.1 \\
\hline 2 & N.A. & N.A. & - \\
\hline 3 & 1199 & 1150 & 4.1 \\
\hline 4 & 1130 & 1007 & 10.9 \\
\hline 5 & 1044 & 919 & 12.0 \\
\hline 6 & 940 & 611 & 35.0 \\
\hline 7 & 983 & 736 & 25.1 \\
\hline 8 & N.A. & N.A. & - \\
\hline 9 & 893 & 622 & 30.3 \\
\hline 10 & 994 & 732 & 26.4 \\
\hline 11 & N.A. & N.A. & - \\
\hline 12 & 953 & 634 & 33.5 \\
\hline
\end{tabular}

N.A. refereeing to sites with model coefficients have not the signs that satisfy the concavity requirements. Therefore, these sites were removed from the analysis. 


\subsection{Impact of Road Geometry on Capacity}

To investigate the relationship between highway geometric characteristics and capacity values for the two elements (tangent and curve), correlation and regression analyses were used. Correlation analysis could help for better understanding of the association between geometric variables and capacity. Regression analysis was conducted to produce several models between tangent/curve characteristics (independent variables) and capacity (dependent variable). Two types of regression analysis were used. The first used a single independent variable as the predictor, the second used multivariate analysis. The criteria used to assess the predictive accuracy of the models were:

- The coefficient of determination $\mathrm{R}^{2}$ must be as high as possible and significant at the 95\% confidence level.

- Each of the independent variables should have regression coefficients that are significantly different from zero, and whose sign should logically explain the effect of this variable on capacity speed.

Having applied these criteria, the best single variable and the best multivariate models were selected.

\section{Tangent Elements}

Correlation coefficients between horizontal alignment characteristics and capacity values for tangent elements, using data presented in Tables 1 and 4, are shown in Table 5.
All tangent characteristics showed directly proportional and significant relationships with capacity except number of side access points that showed inversely proportional correlation, as expected.

Details of the best single and multivariate regression models between capacity and tangent characteristics are shown in Tables 6 and 7.

Based on Table 6 , the best single variable model found was as follows:

$$
\text { Capacity }=-882.30+585.695(L W) .
$$

The resulting coefficient of determinations $\left(\mathrm{R}^{2}\right)$ of 0.94 is considered good which reflects a high goodness-of-fit of the model. It is also found significant at the $95 \%$ confidence level as the significance of $\mathrm{F}$ statistic $<0.001$. Also, the coefficient of independent parameter LW (lane width) was significantly different from zero at the $95 \%$ confidence level as the t-value equals 10.50 . The model has a logical explanation for the effect of lane width on capacity. The positive sign means that as the lane width increases, the capacity increases. In other words, drivers tend to increase their speeds as lane width increases. Thus, capacity also increases.

Based on Table 7, the best multivariate model found for predicting capacity was as follows:

Capacity $=-295.53+313.10(L W)+129.11(S W)+0.17\left(T_{L}\right)$

Table 5, Correlation Coefficients between Capacity and Tangent Characteristics

\begin{tabular}{|c|c|c|c|c|c|}
\hline Tangent Characteristics & LW & SW & T $_{\mathrm{L}}$ & SA & FV \\
\hline Capacity & $0.97 *$ & $0.87 *$ & $0.90^{*}$ & -0.04 & $0.90^{*}$ \\
\hline
\end{tabular}

*Correlation is significant at the 0.01 level (2-tailed).

Table 6, Results of the best Single Variable Model for Capacity on Tangents

\begin{tabular}{|c|c|c|c|c|c|}
\hline Variable & Coefficient & $\mathrm{t}$ & Significance & $\mathrm{R}^{2}$ & $\begin{array}{c}\text { Significance } \\
\text { of F statistic }\end{array}$ \\
\cline { 1 - 4 } Constant & -882.30 & -4.824 & 0.002 & \multirow{2}{*}{0.940} & $<0.001$ \\
\hline LW & 585.69 & 10.492 & $<0.001$ & \\
\hline
\end{tabular}

Table 7, Results of the Best Multivariate Model for Capacity on Tangents

\begin{tabular}{|c|c|c|c|c|c|}
\hline Variable & Coefficient & $\mathrm{t}$ & Significance & $\mathrm{R}^{2}$ & $\begin{array}{c}\text { Significance } \\
\text { of F statistic }\end{array}$ \\
\cline { 1 - 4 } Constant & -295.53 & -7.66 & 0.001 & \multirow{2}{*}{0.999} & $<0.001$ \\
\cline { 1 - 4 } LW & 313.10 & 20.22 & $<0.001$ & \\
\cline { 1 - 3 } $\mathrm{SW}$ & 129.11 & 17.23 & $<0.001$ & & \\
\hline $\mathrm{T}_{\mathrm{L}}$ & 0.17 & 11.36 & $<0.001$ & & \\
\hline
\end{tabular}


The resulting coefficient of determinations $\left(\mathrm{R}^{2}\right)$ and the significance of $\mathrm{F}$ statistic equaled 0.999 and $<0.001$ respectively, which reflects a high goodnessof-fit of the model and the significance of model for use in predication. The coefficient of independent variables LW (lane width), SW (shoulder width) and $\mathrm{T}_{\mathrm{L}}$ (tangent length) were significantly different from zero at the $95 \%$ confidence level as the t-values equal 20.22, 17.23 and 11.36, respectively. The model has a logical explanation for the effect of independent variables on capacity. The positive signs mean that as lane width, shoulder width and tangent length increase, capacity increases.

\section{Curve Elements}

Correlation coefficients between curve characteristics and capacity values are shown in Table 8 .

Based on Table 8, lane width, shoulder width and curve radius characteristics showed significant and positive correlations with capacity. The forward visibility showed positive but insignificant correlation with capacity. Superelevation showed very weak and negative correlation with capacity.

Linear regression analysis was conducted to produce several models between horizontal alignment characteristics of curve elements and capacity values. Details of the best single and multivariate regression models are shown in Tables 9 and 10 .

The best single variable model found was as follows:

$$
\text { Capacity }=540.17+1.1(R)
$$

The resulting coefficient of determinations $\left(\mathrm{R}^{2}\right)$ of 0.87 is considered good. It is also found significant at the $95 \%$ confidence level as the significance of $\mathrm{F}$ statistic $<0.001$. The coefficient of independent parameter $\mathrm{R}$ (curve radius) was significantly different from zero at the $95 \%$ confidence level as the t-value equals 6.8. The t-value showed the relative importance of the variables in model, as the greater the $\mathrm{t}$-value, the greater the contribution of the variables to the model. The model has a logical explanation for the effect of curve radius on capacity. The positive sign means that as the curve radius increases, the capacity increases. In other words, drivers tend to increase their speeds as curve radius increases. Thus, capacity also increases.

The best multivariate model found for predicting capacity was as follows:

$$
\text { Capacity }=-718.1+0.89(R)+391.1(L W)
$$

The resulting coefficient of determinations $\left(\mathrm{R}^{2}\right)$ is 0.97 which is greater than that of the single variable model, and it was found significant at $95 \%$ confidence level as the significance of the F statistic $<0.001$. The coefficients of the independent variables are R (curve radius) and LW (lane width). It can be noticed from Table10 that the hypothesis that each of the coefficients is equal to zero can be rejected at the $95 \%$ confidence level as the t-values are greater than \pm 1.96 . The model has a logical explanation for the effect of the independent variables (curve radius and lane width) on predicting capacity. The positive sign of the independent variable (curve radius) means that as curve radius increases, capacity increases. The positive sign of the independent variable (lane width) means that as lane width increase, the capacity increases, as expected.

Table 8, Correlation Coefficients between Capacity and Curve Characteristics

\begin{tabular}{|c|c|c|c|c|c|}
\hline Curve Characteristics & LW & SW & FV & R & e \\
\hline Capacity & $0.74 *$ & $0.71 *$ & 0.53 & $0.93 * *$ & -0.1 \\
\hline
\end{tabular}

*Correlation is significant at the 0.01 level (2-tailed).

Table 9, Results of the Best Single Variable Model for Capacity on Curves

\begin{tabular}{|c|c|c|c|c|c|}
\hline Variable & Coefficient & $\mathrm{t}$ & Significance & $\mathrm{R}^{2}$ & $\begin{array}{c}\text { Significance } \\
\text { of F statistic }\end{array}$ \\
\cline { 1 - 3 } Constant & 540.17 & 11.24 & $<0.001$ & \multirow{2}{*}{0.87} & $<0.001$ \\
\hline $\mathrm{R}$ & 1.1 & 6.79 & $<0.001$ & \\
\hline
\end{tabular}

Table 10, Results of the best Multivariate Model for Capacity on Curves

\begin{tabular}{|c|c|c|c|c|c|}
\hline Variable & Coefficient & $\mathrm{t}$ & Significance & $\mathrm{R}^{2}$ & $\begin{array}{c}\text { Significance } \\
\text { of F statistic }\end{array}$ \\
\hline Constant & -718.1 & -2.32 & 0.059 & \multirow{2}{*}{0.97} & $<0.001$ \\
\hline $\mathrm{R}$ & 0.89 & 8.84 & $<0.001$ & & \\
\hline LW & 391.1 & 4.08 & 0.006 & & \\
\hline
\end{tabular}




\subsection{Impact of Road Geometry on Capacity Loss}

For the impact of geometric characteristics on capacity loss between the two successive elements (tangent and curve), relevant data in Tables 1,2 and 4 were used to investigate the relationships between them. The examined geometric characteristics include difference in lane width between tangent and curve in the same site, difference in shoulder width, preceding tangent length to curve, forward visibility at curve elements and curve radius.

Linear regression was used to produce the best model that indicates the relationship between percentage of capacity loss (dependent variable) and the examined highway geometric characteristics (independent variables). The best model found was as follows:

$\%$ CapacityLoss $=37.81-0.0633(R)$

Details of the regression analysis for this model are shown in Table 11.

Table 11, Results of the best Regression Model between Capacity Loss and Geometric Characteristics

\begin{tabular}{|c|c|c|c|c|c|}
\hline Variable & Coefficient & $\mathrm{t}$ & Significance & $\mathrm{R}^{2}$ & $\begin{array}{c}\text { Significance } \\
\text { of F statistic }\end{array}$ \\
\hline Constant & 37.81 & 17.61 & $<0.001$ & 0.92 & $<0.001$ \\
\hline $\mathrm{R}$ & -0.0633 & -8.74 & $<0.001$ & & \\
\hline
\end{tabular}

The resulting coefficient of determinations $\left(\mathrm{R}^{2}\right)$ of 0.92 is considered good which reflects a high goodness-of-fit of the model. It was also found significant at the $95 \%$ confidence level as the significance of $F$ statistics $<0.001$. The coefficient of independent parameter (curve radius, R) was significantly different from zero at the $95 \%$ confidence level as the t-value equals -8.74. The model has a logical explanation for the effect of curve radius on capacity loss. The negative sign means that as curve radius decreases, capacity loss increases. In other words, drivers tend to increase their speeds as curve radius increases. Thus, capacity loss decreases.

The results of the best model are summarized in Figure 4. This figure can be used easily to estimate the percentage of capacity loss between two successive elements based on curve radius. For example, if the curve radius equals $350 \mathrm{~m}$, the percentage of capacity loss will equal $15.7 \%$. Based on this figure, also, a curve radius of $600 \mathrm{~m}$ seems to be the threshold value to diminish the capacity loss between two successive elements (tangent and succeeding horizontal curve).

\section{CONCLUSIONS}

The primary objective of this paper is to explore the influence of highway geometric characteristics on capacity and capacity loss. Traffic and geometry data were collected from twelve rural two-lane, two-way road sites in Minoufiya Governorate, Egypt. Each site is consisted of one horizontal curve and the adjoining tangent. To estimate capacity for both tangents and curves, one of the direct-empirical methods based on the observed volumes, speeds and densities, and relying on the fundamental relationships between these parameters by extrapolating free-flow observations was used. General points about the results of this paper may be summarized as follows.

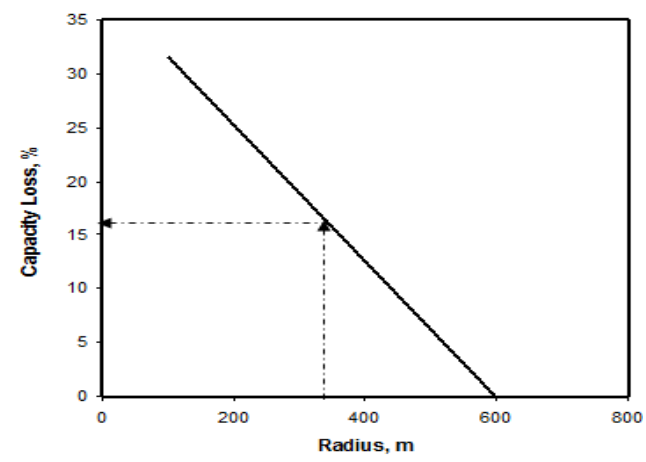

Fig. 4 Determination of percentage of capacity loss $(\%)$

The capacity values at all sites did not reach to the HCM 2000 value (1700 pc/h for one direction under ideal condition) as the geometric characteristics of roads under study are relatively far from the ideal characteristics. In addition, capacity depends on roadway, traffic and driver behavior conditions. Therefore, the values obtained could reflect the conditions for road, traffic and driver of the area under study.

Different regression models were developed between capacity values and geometric characteristics for tangents and curves. These models are very useful and can be used to deal with capacity analysis and evaluation for rural two-lane roads.

For the best multivariate relationship between capacity and tangent characteristics, the significant independent variables are lane width, shoulder width and tangent length, with positive signs. The model has a logical explanation for the effect of independent variables on capacity. The positive signs mean that as lane width, shoulder width and tangent length increase, capacity increases.

In the case of curves, the significant independent variables are lane width and curve radius, with positive signs. The model has a logical explanation for the effect of the independent variables (lane width and curve radius) on predicting capacity. The positive signs mean that as lane width and curve radius increase, the capacity increases, as expected.

The best model that indicates the relationship between capacity loss percentage and horizontal alignment characteristics includes only curve radius, with negative sign, as independent variable. The negative sign means that as curve radius decreases, capacity loss, between tangent and succeeding curve, increases. In other words, drivers tend to increase their speeds as curve radius increases. Consequently, capacity loss decreases. Based on this model, it was 
found that a curve radius with $600 \mathrm{~m}$ seems to be the threshold value to diminish the capacity loss between tangent and succeeding curve.

Finally, the results presented in this paper are based on observations of directional traffic flow in uncongested conditions. Other investigations are recommended considering other traffic conditions (i.e. congested state), upon data availability. Also, such results are applicable to the data range used. Care should be exercised in interpreting any results using data characteristics out of this range.

\section{REFERENCES}

[1] Transportation Research Board (TRB). Highway Capacity Manual (HCM). 4th edition. TRB, National Research Council, Washington, D.C., 2000.

[2] Polus, A., Craus, J., and Livneh M. Flow and Capacity Characteristics on Two-Lane Rural Highways. Transportation Research Record, Transportation Research Board, National Research Council, Washington, D.C., 1991, 1320: 128-134.

[3] Nakamura, M. Research and Application of Highway Capacity in Japan." 2nd International Symposium on Highway Capacity, 1994, Sydney, Australia, 103-112.

[4] Gibreel, G., El-Dimeery, I.A., Hassan, Y. and Easa, S.M. Impact of Highway Consistency on Capacity Utilization of Two-Lane Rural Highways. Canadian Journal of Civil Engineering, 1999, 26(6): 789-798.

[5] Chandra, S., and Kumar, U. Effect of Lane Width on Capacity under Mixed Traffic Conditions in India. Journal of Transportation Engineering, ASCE, 2003, 129(2):155-160.

[6] Yang, X., and Zhang, N. The Marginal Decrease of Lane Capacity with the Number of Lanes on Highway. Proceedings of the Eastern Asia Society for Transportation Studies, 2005, Vol. 5: 739 - 749.

[7] Ben-Edigbe, J. and Ferguson, N. Extent of Capacity Loss Resulting from Pavement Distress. Proceedings of the Institution of Civil Engineers: Transport, 2005, 158 (TR1): 27-32.

[8] Chandra, S. Effect of Road Roughness on Capacity of Two-Lane Roads. Journal of Transportation Engineering, ASCE, 2004, 130(3): 360-364.

[9] Chin, S. M., Franzese, O., Greene, D. L., Hwang, H. L., and Gibson, R. C. Temporary Losses of Highway Capacity and Impacts on Performance. U.S. Department of Energy (DOE), Information Bridge, 04-209, 2002 (Website: http://www.osti.gov/bridge).

[10] Kim, J., and Elefteriadou, L. Estimation of Capacity of Two-Lane Two-Way Highways Using Simulation Model. Journal of Transportation Engineering, ASCE, 2010, 136(1):61-66.
[11] Hashim, I. H. Safety and the Consistency of Geometry and Speed on Rural Single Carriageways. PhD Thesis, School of Civil Engineering and Geosciences, Newcastle University, Newcastle upon Tyne, United Kingdom, 2006.

[12] Hashim, I. H. Analysis of Speed Characteristics for Rural Two-Lane Roads: A Field Study from Minoufiya Governorate, Egypt." Ain Shams Engineering Journal, 2011, 2(1): 43-52.

[13] Yao, J., Rakha, H., Teng, H., Kwigizile, V., and Kaseko, M. Estimating Highway Capacity Considering Two-Regime Models. Journal of Transportation Engineering, ASCE, 2009, 135(9):670-676.

[14] Yao, J., Teng, H., Wei, H., Hu, and S. Estimating Roadway Capacity Using the Simultaneous Spline Regression Model. Journal of Transportation Systems Engineering and Information Technology, 2009, 9(1):87-98

[15] Minderhoud, M., Botma, H., and Bovy, P. Assessment of Roadway Capacity Estimation Methods. Transportation Research Record Transportation Research Board, National Research Council, Washington, D.C., 1997, 1572: 59-67.

[16] Harwood, D., May, AD., Anderson, I., Leiman, L., and Archilla, R. Capacity and Quality of Service of Two-Lane Highways. Midwest Research Institute, Final Report, NCHRP Project 1999, 3-55(3).

[17] Van Arem, B., Van Der Vlist, M. J, De Ruiter, J. C., Muste, M., and Smulders, S. A. Design of the Procedures for Current Capacity Estimation and Travel Time and Congestion Monitoring. DRIVE-11 Project V2044, Commission of the European Communities, (CEC), 1994.

[18] Minderhoud, M., Botma, H., and Bovy, P. Roadway Capacity Using the Product-Limit Approach. 77th Annual Meeting of the Transportation Research Board, Washington D.C, 1998.

[19] Chandra, S., and Sikdar, P. K. Factors Affecting PCU in Mixed Traffic on Urban Roads. Road and Transport Research, ARRB, Australia, 2000, 9(3): 40-50.

[20] Krammes, R. A., and Crowley, K. W. Passenger Car Equivalents for Trucks on Level Freeway Segments." Transportation Research Record, Transportation Research Board, National Research Council, Washington, D.C., 1986, 1091: 10-16.

[21] Polus, A., Fitzpatrick, k., and Fambro, D. Predicting Operating Speeds on Tangent Sections of Two-Lane Rural Highways. Transportation Research Record, Transportation Research Board, National Research Council, Washington, D.C., 2000, 1737: 50-57. 